ScIDice

\section{Evaluation Of the Salivary Levels Of Nerve Growth Factor In Symptomatic Irreversible Pulpitis: An In Vivo Study}

\section{International Journal of Dentistry and Oral Science (IJDOS) ISSN: 2377-8075}

Rukhsaar Akbar Gulzar ${ }^{1 *}$, Ajitha², Haripriya Subbaiyan ${ }^{3}$

${ }^{1}$ Post Graduate Student, Department of Conservative Dentistry and Endodontics, Saveetha Dental College and Hospitals, Saveetha Institute of Medical and Technical Sciences, Saveetha University, Chennai, India.

${ }^{2}$ Professor, Department of Conservative Dentistry and Endodontics, Saveetha Dental College and Hospitals, Saveetha Institute of Medical and Technical Sciences, Saveetha University, Chennai, India.

${ }^{3}$ Senior Lecturer Department of Conservative Dentistry and Endodontics, Saveetha Dental College and Hospitals, Saveetha Institute of Medical and Technical Sciences, Saveetha University, Chennai, India.

\title{
Abstract
}

Introduction: Pain is one of the major complaints of a patient seeking dental treatment. As dental practitioners, one must be aware of the various pathways of pain and the modalities to effectively relives the patient of it during the entire course of treatment. During inflammation of pulp, an elevation in the levels of various inflammatory biomarkers have been observed in saliva. Nerve Growth Factor (NGF) is a protein that has been associated with neutrophic and nociceptive pain. Dental pain

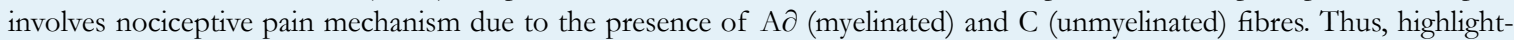
ing a probability of the role of Nerve Growth Factor signalling pathway in dental pain. The present study was conducted to evaluate the salivary levels of NGF in symptomatic irreversible pulpitis.

Materials and Method: Salivary samples were collected from patients diagnosed with symptomatic irreversible pulpitis and control group and were subjected to ELISA test to evaluate the levels of NGF.

Results: A mean of $8.33 \pm 0.60 \mathrm{pg} / \mathrm{ml}$ level of salivary nerve growth factor was observed in symptomatic irreversible which was significantly higher than the levels in the control group.

Conclusion: The elevation in the levels of NGF in saliva during pulpitis suggests the involvement of NGF signalling pathway during pulpal pain which could be used to develop new pharmacological approaches for effective pain management.

Keywords: Pulpitis; Nerve Growth Factor; Saliva; Pain; Nociception.

\section{Introduction}

Ever since the advent of dentistry, the primary reason for a patient seeking dental treatment has been pain. Thus, elimination of pain takes precedence and is highly important in the successful management of a patient. Pain is multifactorial, multidimensional and a complex phenomenon and a dental practitioner must be well versed with the various techniques of relieving the patient of it before, during and after a dental procedure. Various inflammatorybiomarkersand proteins are elevated during dentin-pulp complex pathologies. [1] Nerve Growth Factor which belongs to the family of Neurotrophic factors, is a protein whose levels have been proven to be elevated during inflammation and peripheral- nerve injury. [2]

Growth factors are proteins that play a role in regulating cellular processes like cell proliferations, maturation and differentiation and thus are govern the growth of specific tissues. [3] Neurotrophic factors are comprised of three families of growth factors namely; Nerve Growth Factors also known as Neurotrophins, glial cell line derived neurotrophic factor and certain heterogenous molecules which belong to the family of cytokines. [4] The Neurotrophin family includes the Nerve Growth Factor, Brain Derived neurotrophic Factor, NT-3, NT-4 and NT-6. [5, 6]

Nerve Growth Factor (NGF) was discovered in 1952 by LeviMontalcini and was the first member of the Neurotrophin family.

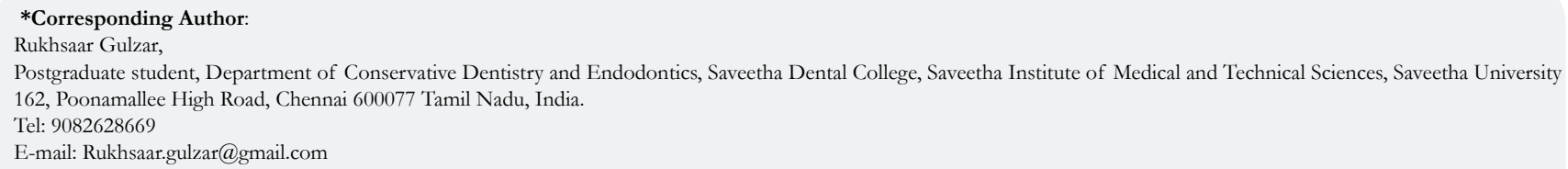

Copyright: Rukhsaar Akbar Gulzar 2021. This is an open-access article distributed under the terms of the Creative Commons Attribution License, which permits unrestricted use, distribution and reproduction in any medium, provided the original author and source are credited. 
[7] It plays a role in maintaining the phenotype and the survival of specific peripheral and central neurons during their phase of development and maturation. It has been shown that certain types sensory neurons involved in nociception require NGF for survival in utero and for their normal development during the initial post-natal phase where as in adulthood NGF is mainly involved in inflammation and hyperalgesia. [8] Nerve Growth Factor signalling is an active process which is involved in nociceptive and neuropathic pain. Nociceptive pain involves activation of nociceptors by a noxious stimulus. [9] Dental pulp contains the A $\partial$ (myelinated) and C (unmyelinated) fibres which governs the pulpal pain in response to a noxious stimulus. [10]

Previously our team had conducted numerous clinical studies[11, 14], case reports [15], in vitro studies [16, 19], surveys [20, 21] and reviews $[22,25]$ in various aspects of endodontics and conservative dentistry over the past five years from which the idea of the present study has stemmed. Thus, the present study was conducted to evaluate the levels of Nerve Growth Factor in saliva of patients suffering from symptomatic irreversible pulpitis.

\section{Aim and Objectives}

The aim of the present study was to evaluate the salivary level of Nerve Growth Factor in condition of symptomatic irreversible pulpitis.

The following were the objectives of the study:

To determine and compare the levels of salivary NGF in patients diagnosed with symptomatic irreversible pulpitis and symptom free healthy individuals.

To determine the significance of salivary NGF as a diagnostic marker for pain in symptomatic irreversible pulpitis.

To evaluate the pharmacological implication of the involvement of neurotrophic factors in eliciting pulpal pain.

\section{Materials and Methods}

The present study comprised of two groups with a sample size of 10 per group. Group A comprised of patients in whom a single tooth was diagnosed with symptomatic irreversible pulpitis and Group B was the control group of symptom free healthy individuals. Patients with multiple decayed or multiple pulpally involved teeth, patients with periodontitis and gingivitis and patients with any other systemic condition were excluded from the study. The patients were informed about the study and asked to sign a consent form.

The salivary samples were collected between 9 am in the morning and 12 noon by asking the patients to pool their saliva and then spit it in the given sterile containers. The patients were abstained from eating or drinking two hours prior to the collection of saliva. The samples were then analysed for the level of Nerve Growth Factor.

Human NGF ELISA Kit was purchased from Thermo scientific, USA. Addition of $100 \mu \mathrm{L}$ of each standard and saliva was done in to appropriate pre coated wells. The wells were covered and incubate for 2.5 hours at room temperature or overnight at $4^{\circ} \mathrm{C}$ with gentle shaking. The solution was discarded after which each well was filled with Wash Buffer $(300 \mu \mathrm{L})$ using a multi-channel Pipette and washed 4 times with $1 \mathrm{X}$ Wash Buffer. To each well, $100 \mu \mathrm{L}$ of $1 \mathrm{X}$ prepared biotinylated antibody specific to human nerve growth factor was added and Incubate for 1 hour at room temperature with gentle shaking. Next, $100 \mu \mathrm{L}$ of prepared StreptavidinHRP solution was added to each well and incubate for 45 minutes at room temperature with gentle shaking followed by addition of $100 \mu \mathrm{L}$ of TMB Substrate to each well. It was incubated for 30 minutes at room temperature in the dark with gentle shaking. The plates were evaluated within 30 minutes of stopping the reaction. The absorbance was measured on an ELISA plate reader set at $450 \mathrm{~nm}$.

The data obtained from the experiment was expressed as Mean +/- standard deviation. For statistical analysis, data was subjected to one-way analysis of variance (ANOVA) followed by Student's t-test. The Dunnett post hoc analysis was performed to compare each experimental test group's mean result to a control group's mean result. A level of $\mathrm{P}<0.01$ was taken as significant. The statistical analysis was done using the SPSS statistical package (version).

\section{Results and Discussion}

The results of the present study demonstrate a significantly higher level of Nerve Group Factor $(* \mathrm{P}<0.01)$ in the salivary samples of the patients diagnosed with symptomatic irreversible pulpitis $\left(8.33 \pm 0.60^{*}\right)$ as compared to the control group $\left(4.03 \pm 0.47^{*}\right)$ (Figure 1).

Figure 1: Levels of nerve growth factor in symptomatic irreversible pulpitis. The $X$ axis represents the two groups under the study and the $y$ axis represents the levels of nerve growth factor as detected in the saliva.

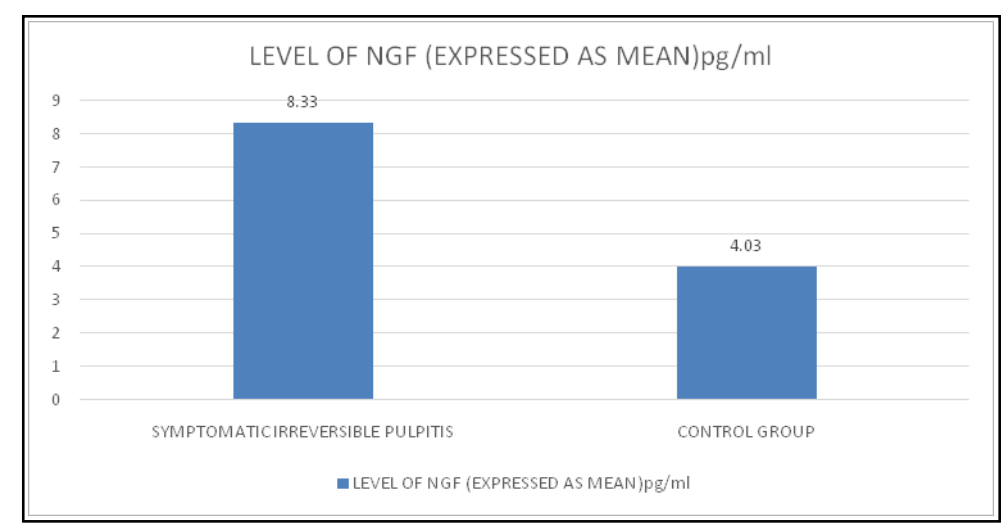


Saliva is considered as the reflection of the body's state of health and disease and a variety of analytes from systemic sources reach the oral cavity through various pathways and are found in saliva. [26] This is a novel study where the levels of salivary NGF has been evaluated in patients diagnosed with symptomatic irreversible pulpitis. According to the results of the present study, the levels of salivary NGF were significantly higher in patients with symptomatic irreversible pulpitis as compared to healthy individuals.

Nerve Growth Factor acts by binding to two types of surface receptors: Neurotrophin receptors p75 for which is has low affinity and tropomyosin-related kinase A (trkA) receptor for which it has high affinity. [27] The trkA receptor is selectively expressed on the peripheral terminals of A-delta nerve fibres and unmyelinated Cfibers. [27, 28] According to the "neurotrophic factor hypothesis" and the classical neurotrophic model, the target tissues synthesize and released and release NGF during embryonic development which promotes the growth, differentiation, and survival of neurons in a dose dependent manner. [29] During embryogenesis, the sensory neurons of the dorsal root ganglia (DRG) shows a higg expression of $\operatorname{TrkA}$; however, postnatally there is a shift of NGF-trkA signalling from promoting the growth of neuron and its survival to regulating peripheral nervous system's sensitivity to a noxious stimulus. [30]

Nociceptors which are located in peripheral tissues are activated in response to noxious stimuli thereby causing nociceptive pain. Any stimulus (eg, chemical, thermal, or mechanical) that either damages or threatens to cause damage to normal tissues is a noxious stimuli. Following noxious stimuli (eg, injury and inflammation), NGF is produced and released by peripheral tissues secondary to the release of inflammatory cytokines, such as interleukin-1 and tumor necrosis factoralpha. Effects on pain signalling is modulated by the binding of NGF to the trkA receptors on multiple targets. [28] Once the NGF-trkA complex is formed, it gets internalized and is transported retrogradely to DRG cell bodies where it modulates and /or increases the expression of a variety of cell surface receptors involved in nociception. [16] The binding of NGF to the trkA receptors located on mast cells causes an additional effect on pain processing. This process is proinflammatory and a positive feedback loop is generated by eliciting the release of inflammatory mediators such as histamine, serotonin or 5-hydroxytryptamine (5-HT), protons, as well as NGF itself. [28, 31] Thus, NGF signalling plays two roles, it increase the expression of nociceptive receptors located peripherally and pronociceptive neurotransmitters located centrally, and in response to inflammation, it also sensitizes adjacent nociceptive neurons.

A study conducted Woodnut et.al evaluated the expression of neurotrophin receptors and NGF in nonneuronal cells of normal and injured tooth pulp. The study showed an upregulation of NGF in injured pulp and its accumulation in surviving odontoblast cells. [32]

A study conducted by Mitsiadis et.al showed a weak expression of NGF, p75NTR and dental pulp fibroblasts and odontoblasts of intact functional teeth, while a strong expression of NGF and p75NTR molecules was seen in nerve fibres that innervated the dental pulp. An upregulation of NGF and TrkA was seen in carious and injured teeth in odontoblasts surrounding the injury sites. This indicated a correlation between NGF signalling and dental tissue repair events. [33]

Non-steroidal anti-inflammatory (NSAIDs) are routinely used for the management and control of pain. [34] The discovery of Nerve Growth Factor has led to the exploration of newer pharmacological approaches targeting the NGF pathway for effective pain management. These approaches mainly aim at sequestration of NGF, prevention of binding of NGF to trkA receptor and inhibition of trkA function. Nerve Growth Factor sequestration involves the use of NGF antibody. [2] The prevention of binding of the factor to its receptor was done using mouse monoclonal anti-trkA, MNAC13. It was capable of inducing analgesia in models of inflammatory and neuropathic pain. A synergistic was observed when it was used in combination with low-dose opioids. However, analogous species were not introduced in to clinical trials due to lack of equivalent humanized antibody. [35] k252a is a small-molecule protein kinase inhibitor that inhibits the activation of the entire tropomyosin receptor kinase family ( $\operatorname{trk} \mathrm{A}, \operatorname{trkB}$, and $\operatorname{trkC}$ ). However, due to lack of specificity, no human trials were ever been initiated. [36]

\section{Conclusion}

The activity of NGF and its interaction with trkA in nociceptive and inflammatory pain has been well established. The sequestration of NGF and inhibition of trkA signaling have demonstrated a consistent analgesic effect in the preclinical models of inflammatory and visceral pain.

The present study demonstrates an elevation of the levels of nerve Growth Factor in saliva during pulpitis suggesting its role in inflammation of pulp and dental pain. This could serve as a non-invasive prognostic marker for pulpitis and could form the basis for the development of new pharmacological approaches for effective management of dental pain.

\section{References}

[1]. Emilia E, Neelakantan P. Biomarkers in the dentin-pulp complex: role in health and disease. J ClinPediatr Dent. 2015 Winter;39(2):94-9.Pubmed PMID: 25951306.

[2]. Chang DS, Hsu E, Hottinger DG, Cohen SP. Anti-nerve growth factor in pain management: current evidence. J Pain Res. 2016 Jun 8;9:373-83.Pubmed PMID: 27354823.

[3]. Hardy K, Spanos S. Growth factor expression and function in the human and mouse preimplantation embryo. J. Endocrinol. 2002 Feb 1;172(2):22136.

[4]. Kerschensteiner M, Stadelmann C, Dechant G, Wekerle H, Hohlfeld R Neurotrophic cross-talk between the nervous and immune systems: implications for neurological diseases. Ann Neurol. 2003 Mar;53(3):292-304.Pubmed PMID: 12601697.

[5]. Vega JA, García-Suárez O, Hannestad J, Pérez-Pérez M, Germanà A. Neurotrophins and the immune system. J. Anat. 2003 Jul;203(1):1-9.

[6]. Razavi S, Nazem G, Mardani M, Esfandiari E, Salehi H, Esfahani SH. Neurotrophic factors and their effects in the treatment of multiple sclerosis. Adv. Biomed. Res. 2015;4:53.

[7]. Levi-Montalcini R. The nerve growth factor: thirty-five years later. EMBO J. 1987 May;6(5):1145-54.

[8]. Lewin GR, Mendell LM. Nerve growth factor and nociception. Trends Neurosci. 1993 Sep 1;16(9):353-9.

[9]. Cohen SP, Mao J. Neuropathic pain: mechanisms and their clinical implications. Bmj. 2014 Feb 5;348:f7656.

[10]. Ingle JI, Bakland LK, Baumgartner JC. Ingle's endodontics 6. Ontario: BC Decker.2008; 136-137.

[11]. Rajendran R, Kunjusankaran RN, Sandhya R, Anilkumar A, Santhosh R, Patil SR. Comparative evaluation of remineralizing potential of a paste con- 
taining bioactive glass and a topical cream containing casein phosphopeptide-amorphous calcium phosphate: An in vitro study. Pesqui Bras OdontopediatriaClinIntegr. 2019;19(0):4668.

[12]. Jenarthanan S, Subbarao C. Comparative evaluation of the efficacy of diclofenac sodium administered using different delivery routes in the management of endodontic pain: A randomized controlled clinical trial. J Conserv Dent. 2018 May-Jun;21(3):297-301.Pubmed PMID: 29899633.

[13]. Khandelwal A, Palanivelu A. Correlation between dental caries and salivary albumin in adult population in Chennai: An in vivo study. Braz. Dent. Sci. 2019 Apr 30;22(2):228-33.

[14]. Ramarao S, Sathyanarayanan U. CRA Grid - A preliminary development and calibration of a paper-based objectivization of caries risk assessment in undergraduate dental education. J Conserv Dent. 2019 Mar-Apr;22(2):185-190. Pubmed PMID: 31142991.

[15]. MalliSureshbabu N, Selvarasu K, V JK, Nandakumar M, Selvam D. Concentrated Growth Factors as an Ingenious Biomaterial in Regeneration of Bony Defects after Periapical Surgery: A Report of Two Cases. Case Rep Dent. 2019 Jan 22;2019:7046203.Pubmed PMID: 30805222.

[16]. Nandakumar M, Nasim I. Comparative evaluation of grape seed and cranberry extracts in preventing enamel erosion: An optical emission spectrometric analysis. J Conserv Dent. 2018 Sep-Oct;21(5):516-520.Pubmed PMID: 30294113

[17]. Siddique R, Sureshbabu NM, Somasundaram J, Jacob B, Selvam D. Qualitative and quantitative analysis of precipitate formation following interaction of chlorhexidine with sodium hypochlorite, neem, and tulsi. J Conserv Dent. 2019 Jan-Feb;22(1):40-47.Pubmed PMID: 30820081.

[18]. Teja KV, Ramesh S, Priya V. Regulation of matrix metalloproteinase-3 gene expression in inflammation: A molecular study. J Conserv Dent. 2018 Nov;21(6):592-6.

[19]. Govindaraju L, Neelakantan P, Gutmann JL. Effect of root canal irrigating solutions on the compressive strength of tricalcium silicate cements. Clin Oral Investig. 2017 Mar;21(2):567-571.Pubmed PMID: 27469101.

[20]. Manohar MP, Sharma S. A survey of the knowledge, attitude, and awareness about the principal choice of intracanal medicaments among the general dental practitioners and nonendodontic specialists. Indian J Dent Res. 2018 Nov-Dec;29(6):716-720.Pubmed PMID: 30588997.

[21]. Janani K, Sandhya R. A survey on skills for cone beam computed tomography interpretation among endodontists for endodontic treatment procedure. Indian J Dent Res. 2019 Nov-Dec;30(6):834-838.Pubmed PMID: 31939356

[22]. Rajakeerthi R, Nivedhitha MS. Natural Product as the Storage medium for an avulsed tooth-A Systematic Review. Cumhur. Dent. J. 2019;22(2):24956.
[23]. Azeem RA, Sureshbabu NM. Clinical performance of direct versus indirect composite restorations in posterior teeth: A systematic review. J Conserv Dent. 2018 Jan-Feb;21(1):2-9.Pubmed PMID: 29628639.

[24]. Poorni S, Srinivasan MR, NivedhithaMS.Probiotic strains in caries prevention: A systematic review. J Conserv Dent. 2019; 22(2):123-8.

[25]. Siddique R, Nivedhitha MS. Effectiveness of rotary and reciprocating systems on microbial reduction: A systematic review. J Conserv Dent. 2019 Mar-Apr;22(2):114-122.Pubmed PMID: 31142978.

[26]. Devi TJ.Saliva-a potential diagnostic tool. IOSR Journal of Dental and Medical Sciences.2014;13(2):52-7.

[27]. Hefti FF, Rosenthal A, Walicke PA, Wyatt S, Vergara G, Shelton DL, et al. Novel class of pain drugs based on antagonism of NGF. Trends Pharmacol Sci. 2006 Feb;27(2):85-91.Pubmed PMID: 16376998.

[28]. Mantyh PW, Koltzenburg M, Mendell LM, Tive L, Shelton DL. Antagonism of nerve growth factor-TrkAsignaling and the relief of pain. Anesthesiology. 2011 Jul;115(1):189-204.Pubmed PMID: 21602663.

[29]. Yuen EC, Howe CL, Li Y, Holtzman DM, Mobley WC. Nerve growth factor and the neurotrophic factor hypothesis. Brain Dev1. 1996 Sep 1;18(5):3628.

[30]. Bennett DL. Neurotrophic factors: important regulators of nociceptive function. Neuroscientist. 2001 Feb;7(1):13-17.

[31]. McKelvey L, Shorten GD, O'Keeffe GW. Nerve growth factor-mediated regulation of pain signalling and proposed new intervention strategies in clinical pain management. J Neurochem. 2013 Feb;124(3):276-89.Pubmed PMID: 23157347.

[32]. Woodnutt DA, Wager-Miller J, O'Neill PC, Bothwell M, Byers MR. Neurotrophin receptors and nerve growth factor are differentially expressed in adjacent nonneuronal cells of normal and injured tooth pulp. Cell Tissue Res. 2000 Feb;299(2):225-36.Pubmed PMID: 10741463.

[33]. Mitsiadis TA, Magloire H, Pagella P. Nerve growth factor signalling in pathology and regeneration of human teeth. Sci Rep. 2017 May 2;7(1):1327. Pubmed PMID: 28465581.

[34]. Priyadharshini R, Murthykumar K. Cox2-Inhibitors in the management of pulpal pain-a review. J. Pharm. Sci. Res. 2016 Jun 1;8(6):442.

[35]. Ugolini G, Marinelli S, Covaceuszach S, Cattaneo A, Pavone F. The function neutralizing anti-TrkA antibody MNAC13 reduces inflammatory and neuropathic pain. ProcNatlAcadSci U S A. 2007 Feb 20;104(8):2985-90. Pubmed PMID: 17301229 .

[36]. Winston JH, Toma H, Shenoy M, He ZJ, Zou L, Xiao SY, et al. Acute pancreatitis results in referred mechanical hypersensitivity and neuropeptide up-regulation that can be suppressed by the protein kinase inhibitor k252a. J Pain. 2003 Aug;4(6):329-37.Pubmed PMID: 14622690. 